\title{
Computed tomography-guided percutaneous radiofrequency and laser ablation for the treatment of osteoid osteoma - long-term follow-up from 5 to 10 years
}

\author{
Tomasz Lorenc', Hanna Kocoń2, Marek Gołębiowski' \\ ${ }^{1} 1^{\text {st }}$ Department of Clinical Radiology, Medical University of Warsaw, Poland \\ 2Department of Orthopedics and Traumatology of the Musculoskeletal System, Medical University of Warsaw, Poland
}

\section{Abstract}

\begin{abstract}
Purpose: The impact of computed tomography (CT)-guided, percutaneous radiofrequency ablation and interstitial laser ablation (ILA) on the management of patients with osteoid osteoma was studied. This was carried out by assessing immediate and long-term clinical outcomes, the complication rate, and repeat therapy effectiveness in recurrent patients who have already experienced percutaneous ablation.
\end{abstract}

Material and methods: Consecutive patients with osteoid osteoma were assessed before the interventional treatment in a single centre from 2010 to 2015. Patient demographics, complications, and recurrence were recorded. The pain was evaluated with Visual Analogue Scale (VAS). Percutaneous procedures were performed by means of radiofrequency thermoablation or ILA. Epidural or regional anaesthesia in the CT suite was applied in all procedures. Success, whether primary or secondary, was measured as complete pain relief without evidence of recurrence after the first or second procedure, respectively. Osteoid osteoma characteristics, procedure overview, and technical success were looked for in pre-procedural and procedural scans.

Results: Eighty-three per cent of osteoid osteomas were located in lower extremities, $56 \%$ of tumours were intracortical, and $83 \%$ of osteoid osteomas were extra-articular. The mean pre-procedure VAS score was $8.5 \pm 0.8$, while the overall primary success rate of radiofrequency thermoablation and ILA was $87.5 \%$. No major complications were noted. The mean follow-up period for patients in was 7.5 years (5.0-10.2 years).

Conclusions: Percutaneous, CT-guided thermoablation proved to be effective and should become the method of choice in osteoid osteoma treatment because of its minimal invasiveness. Our results show that there is no risk of very late recurrence after achieving primary and secondary treatment success.

Key words: osteoid osteoma, radiofrequency ablation, laser ablation, multidetector computed tomography.

\section{Introduction}

In 1930 Bergstrand first described osteoid osteoma (OO) as a benign tumour. Jaffe followed this concept in 1935 $[1,2]$. The tumour accounts for $\sim 10$ to $12 \%$ of all benign bone tumours, most frequently occurring in the second and third decades of life, with a male preponderance [3-5]. The tumour is composed of vascularised callus and primitive (woven) bone (called a nidus) surrounded by a zone of reactive sclerosis, where compact bone of different degrees of maturity is observed [6]. The tumour is found mainly in long bones; over $50 \%$ of cases are located in the femur or the tibia $[7,8]$. The lesion is usually located in the proximal part of the femur (diaphysis) and rarely in the epiphysis. Based on its location in an axial cross-section, OO is described as subperiosteal, intracortical, endosteal, or medullary, and depending on its relation to the articular capsule attachment, as extra- or intra-articular

\section{Correspondence address:}

Dr. Tomasz Lorenc, 15t Department of Clinical Radiology, Medical University of Warsaw, Chałubińskiego 5 Str., 02-004 Warsaw, Poland, e-mail: tlorenc@wum.edu.pl Authors' contribution:

A Study design · B Data collection · C Statistical analysis · D Data interpretation · E Manuscript preparation · F Literature search · G Funds collection 
[6,9]. The leading clinical manifestation of OO is pain [7]. The pain typically intensifies at night and subsides quickly after the administration of salicylates (within about 30 minutes) [10]. Prostaglandins were found to have taken active part in the production of pain in patients with OO. The elevation of the prostaglandin level from 100 to 1000 times the normal level was found to take place within the nidus of the lesion [11]. Besides the production of prostaglandins in the lesion, the pain is related to the presence of unmyelinated nerve fibres within it $[12,13]$. The pain may be accompanied by local oedema and tenderness and, in children, by more dramatic manifestations, such as stunted growth and neurological manifestations. With intra-articular tumours, the presentation may be misleading and suggest a primary articular pathology. The manifestations include tenderness, mobility limitation, contracture, and joint effusion. The lesion causes synovial hypertrophy and articular cartilage damage, which may lead to early onset of degenerative changes [7]. Laboratory workup is usually negative. Effective surgical treatment requires the complete removal of the nidus [14]. Depending on the lesion size and location, the extent of bone resection varies from minimal to extensive. If a substantial amount of cortical bone is removed, there is risk of fracture at weight bearing sites. In such cases internal fixation and bone grafting may be prove necessary. Due to the implementation of improved methods, taking advantage of computed tomography, the precise localisation of an OO has been made possible in the treatment of this lesion with more limited operations, especially percutaneous ablation $[4,15]$. Computed tomography (CT)-guided percutaneous radiofrequency thermoablation (RFA) and interstitial laser ablation (ILA) are effective techniques that have been universally acknowledged as a minimally invasive, safe, and cost-effective cure for OO [16-19].

However, the long-term efficacy of ablation in the treatment of $\mathrm{OO}$ has been examined more closely. What was found was that an important parameter concerning delayed OO recurrences was reported up to 10 years after surgical resection and RFA with CT-guidance [20-23]. The impact of CT-guided, percutaneous RFA or ILA on the management of patients was closely examined by evaluating the exclusion rate, immediate and long-term clinical outcomes with a minimum of a 5-year follow-up, the rate of complications, and the effectiveness of repeat therapy in recurrent patients having already experienced percutaneous ablation, despite this group being small.

\section{Material and methods}

\section{Demographic data}

Between 2010 and 2015, 20 patients underwent qualification for percutaneous $\mathrm{OO}$ thermoablation at a single centre. All procedures performed in studies involving human participants were in accordance with the ethical standards of the institutional review board. Informed consent was obtained from all individual participants included in the study. The age of patients ranged from 5 to 34 years old (mean: 19 years old). Our population consisted of 11 males and 9 females, giving a sex ratio of $1.2: 1$.

\section{Analysis and management of osteoid osteoma}

All patients had typical histories, and we confirmed the presence of a nidus using CT examinations, also in order to obtain detailed information. CTs were performed on a 64-detector CT scanner (Aquillion 64; Toshiba Medical Systems Corporation, Otawara, Japan). The images were reconstructed with a section thickness of $0.5 \mathrm{~mm}$, using a bone reconstruction kernel. Images were assessed on a dedicated workstation (IntelliSpace Portal, Philips Healthcare, Eindhoven, Nederland) at a single centre. Baseline data included OO location and imaging features. The nidus maximal diameter was calculated on axial planes, and the maximal area of the nidus was calculated on reformatted planes using multiplanar CT images for the benefit of manual measurements. For the softwareaided CT measurements of the nidus volume, images were evaluated at a workstation (IntelliSpace Portal), and volume-rendered images were used in CT volume calculations. By using the auto counter tool, no manual adjustments were performed, so as to obtain optimal automated nidal volume calculations. Lesions were classified on the basis of location: subperiosteal, intracortical, endosteal, or medullary in accordance with the criteria of Kayser et al [9]. Based on their relation to the articular capsule attachment, OO were divided into extra- or intra-articular. Nidus calcifications were also assessed. Perinidal cortical or intramedullary reactive sclerosis was measured. In order to access each $\mathrm{OO}$ and type of ablation, procedural notes were reviewed to determine the number of osseous channels used. RFA and ILA procedures were defined to be radiologically successful when an RFA electrode or ILA needle were successfully placed centrally in the nidus. Then the distance between the nidus and skin at the place of needle entry was measured.

\section{Patient selection}

Whether to treat by RFA or ILA, a multidisciplinary musculoskeletal oncology consultative meeting was held. The clinical diagnosis of OO was suspected when predominantly nocturnal pain, not related to physical activity, was typically relieved by NSAIDs. If a patient suffered from clinically significant pain, evaluated on a 0-10 Visual Analogue Scale (VAS) over $24 \mathrm{~h}$ prior, this was considered an eligibility criterion. Pain was considered clinically significant if it reached a score of 6 or more on VAS [24]. This algic threshold was considered an inclusion criterion regardless of clinically significant functional limitations. 


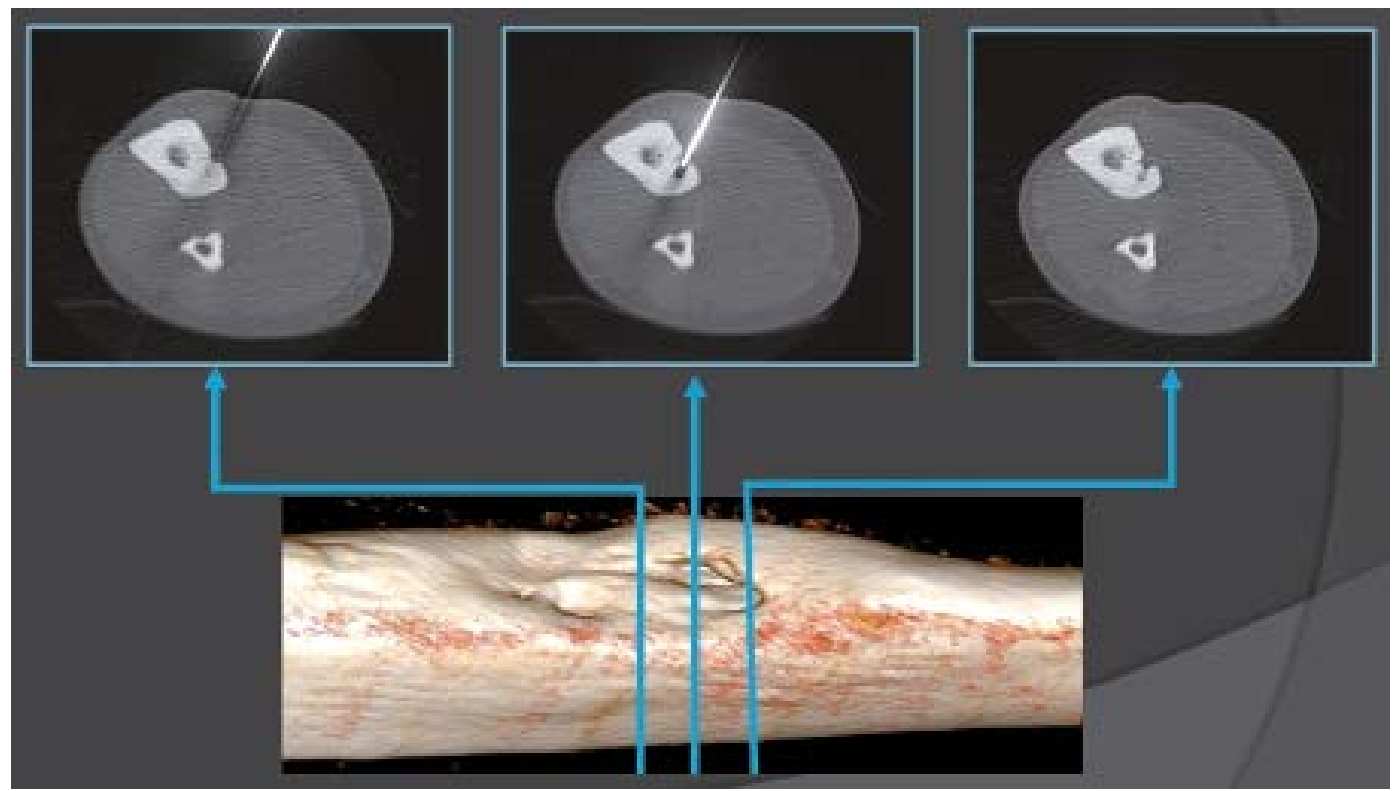

Figure 1. Multislice computed tomography (CT) fluoroscopy allows the guidance and placement of the needle to be monitored in 3D. Acquisition of 3 contiguous $\mathrm{CT}$ slices of varying thickness permits a volumetric approach with precise management of the patient's z-axis and accurate depiction of the needle progression when bone drilling

In addition to using good medical judgment when seeking potential candidates for this therapy, the following exclusion criteria were considered:

- target lesion $<1 \mathrm{~cm}$ away from the skin, neurovascular bundles, bowel, hollow viscera, or regions of cartilage/ bone growth plate,

- pregnant female,

- active infection,

- contraindication to deep sedation/general anaesthesia,

- lack of written informed consent.

When not all clinical or radiological criteria were met, a biopsy was performed before or during the RFA or ILA procedure. Neither the absence of histological confirmation of the diagnosis nor prior treatment having been performed were considered to be an exclusion criterion.

\section{Pre-procedure}

Before the percutaneous thermoablation procedure was carried out it was carefully explained to all patients, and alternative treatments, such as open surgery or pharmaceutical treatment, were presented. Before ablation, all patients had to give their informed consent (in the case of minors, from parents). Prior to treatment, all patients were evaluated by an experienced orthopaedic surgeon (HK). The evaluation constituted a full physical examination including an assessment of the pain level.

\section{Procedure}

CT guidance was used in the performance of RFA and laser ablations (Toshiba Aquilion 64, Toshiba Medical Systems Corporation, Japan). The procedures took place on an in-patient basis and were carried out by an interven- tional radiologist and orthopaedic surgeon in a CT room. A CT scanner was then used to localise the tumour nidus, guide the needle placement within the tumour nidus, and depict carbonisation. The use of $0.5-\mathrm{mm}$-thick contiguous sections through the region of interest helped localise the tumour at CT. After precisely locating the tumour by CT scanning, the skin entry point and approach were determined. The dimensions of the nidus were measured at $\mathrm{CT}$, which enabled the measurement of the amount of energy required to coagulate the tumour. Upon applying bone drilling, CT-fluoroscopy guidance was used to depict needle progression (Figure 1).

Because the pain during the penetration of the needle into the nidus is excruciating, patients were given spinal anaesthesia in the case lower extremity lesions. Those with a lesion in an upper limb were given a regional nerve block. Following a small skin incision, each OO nidus was accessed with a 14-gauge Bonopty (AprioMed AB, Uppsala, Sweden) coaxial bone biopsy system (Figure 2). At this moment tissue sampling was attempted for a few lesions. Before treatment, a typical broad-spectrum antibiotic was applied.

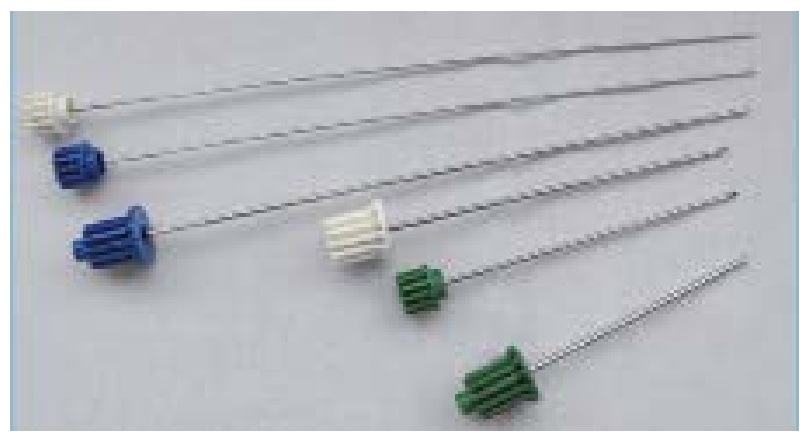

Figure 2. A 14-gauge Bonopty (AprioMed AB, Uppsala, Sweden) coaxial bone biopsy system 


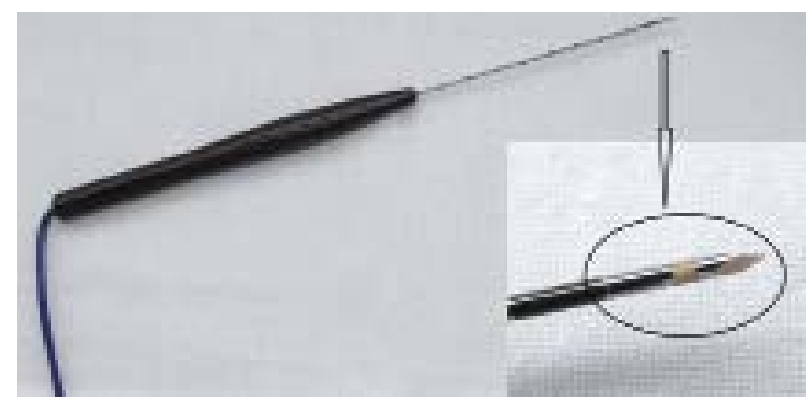

Figure 3. A) RF ablation needle (Celon ProSurge, Olympus), with the active tip (B)

\section{Computed tomography-guided percutaneous bipolar radiofrequency ablation procedure}

The internal drill or stylet of the Bonopty Penetration Set was exchanged with the radiofrequency electrode. To ensure that there was no contact between the cannula and electrode, the cannula was retracted over the electrode. An 18-gauge bipolar electrode (Celon ProSurge micro, Olympus, Germany) was used for RF ablation (Figure 3). We used non-cooled electrodes with $9 \mathrm{~mm}$ active tips in lesions less than $1 \mathrm{~cm}$ and $15 \mathrm{~mm}$ in lesions more than $1 \mathrm{~cm}$ in maximum diameter. With the electrode connected to the RF generator, power was set at $3 \mathrm{~W}$ and energy application increased to $5 \mathrm{~W}$ max. Once a resistance of $900 \Omega$ was reached, the procedure was terminated. Because we used a bipolar RF system, there was no requirement for the placement of grounding pads.

\section{Laser ablation procedure}

To perform ILA, a portable, continuous-wave, semiconductor diode laser (model CTL Doris Plus, CTL, Warsaw, Poland) with an 810-nm wavelength was used. Laser energy was delivered with a flexible, single-use, bare-tipped, $400-\mu \mathrm{m}$ fibre with polymer cladding. The fibre was not radiopaque; therefore, before insertion, the fibre was inserted into the 18-gauge spinal needle, and its length adapted and marked. Upon location confirmation of the tip of the 18-gauge spinal needle within the centre of the nidus with CT, the $400-\mu \mathrm{m}$ fibre was placed in the needle. It was then withdrawn by $5 \mathrm{~mm}$ to expose the tip of the

\section{Table 1. Excluded procedures}

\begin{tabular}{|c|c|c|}
\hline Candidate & Nidus location & $\begin{array}{l}\text { Contraindications } \\
\text { to thermoablation }\end{array}$ \\
\hline I & Pedicle of vertebral arch & $\begin{array}{l}\text { Less than } 1 \mathrm{~cm} \\
\text { to neural structure }\end{array}$ \\
\hline$\|$ & The head of the fibula & $\begin{array}{l}\text { Less than } 1 \mathrm{~cm} \\
\text { to neural structure }\end{array}$ \\
\hline III & Talus & Too close to the skin \\
\hline IV & Femur & Lack of consent \\
\hline
\end{tabular}

bare fibre within the tumour. The diode laser was set in the continuous-wave mode delivering $2 \mathrm{~W}$ of power for a calculated number of seconds to achieve total energy. The amount of energy delivered was adjusted according to the formula $(\mathrm{NS} \times 100 \mathrm{~J})+200 \mathrm{~J}$, where NS is nidus size in millimetres. A maximum energy of $1200 \mathrm{~J}$ was most commonly applied to avoid damage to surrounding structures and to coagulate the nidus.

\section{Discharge}

All patients were hospitalised for 1-2 nights after RFA or ILA, depending on the severity of the post-procedural pain. Acetaminophen was recommended for routine pain control, and patients were prescribed acetaminophen with codeine for PRN pain control during the first $24 \mathrm{~h}$ of the post-procedure period. Before being discharged, each patient was assessed and examined for bleeding, swelling, skin burn, neurovascular complications, and other procedure-related problems, to assess the technical success rate. All patients were instructed to avoid strenuous high impact activity for 6 weeks after the procedure.

\section{Clinical success rate}

OO-related pain was defined as pain of similar location and quality compared to originally reported symptoms. VAS was used to assess a patient's pain levels [24]. Primary clinical success was measured as OO-related pain 1 month after RFA or ILA without additional intervention such as repeat RFA or repeat ILA. Long-term treatment success was defined as a lack of medically documented OO recurrence with no OO-related pain at the time of follow-up.

\section{Follow-up}

After the first month of the procedure, a full physical examination was carried out. Data on direct and indirect changes in pain levels and function were also assessed. Subsequently patients were evaluated every 3 months during the first year and annually thereafter. All patients were informed that $\mathrm{OO}$ is a bone tumour, and the followup was necessary to confirm full recovery. For patients under 18 years of age, the patient's legal guardian was interviewed. The patients were informed that in the case of any pain recurrence, they should immediately contact the department.

\section{Results}

\section{Rejection from percutaneous thermoablation}

Four patients (4/20) failed to meet the inclusion criteria and were excluded from thermoablation. Contraindications to percutaneous RFA or ILA are shown in Table 1. 
Table 2. Data of the treated patients including systems used, procedure characteristics, and follow-up (years)

\begin{tabular}{|c|c|c|c|c|c|}
\hline $\begin{array}{l}\text { Patient number/ } \\
\text { age (years)/gender }\end{array}$ & $\begin{array}{c}\text { Type } \\
\text { of ablation }\end{array}$ & $\begin{array}{l}\text { Number } \\
\text { of osseous } \\
\text { channels }\end{array}$ & $\begin{array}{l}\text { Length of needle tract from } \\
\text { entry point to the nidus } \\
\text { (mm) }\end{array}$ & $\begin{array}{c}\text { Perinidal reactive sclerosis } \\
\text { and cortical thickness } \\
\text { at entry point (mm) }\end{array}$ & $\begin{array}{l}\text { Duration of clinical } \\
\text { follow-up (years) }\end{array}$ \\
\hline $1 / 12 / F$ & Laser ablation & 1 & 66 & 3.0 & 5.3 \\
\hline 2/16/M & Laser ablation & 1 & 22 & 6.7 & 5.0 \\
\hline $3 / 32 / \mathrm{M}$ & Laser ablation & 1 & 28 & 1.1 & 5.7 \\
\hline $4 / 26 / \mathrm{M}$ & Laser ablation & 1 & 29 & 7.0 & 6.1 \\
\hline $5 / 14 / F$ & Celon ProSurge & 1 & 21 & 2.0 & 7.1 \\
\hline 6/5/M & Celon ProSurge & 1 & 43 & 9.0 & 7.5 \\
\hline $7 / 21 / M$ & Celon ProSurge & 1 & 24 & 1.2 & 7.2 \\
\hline $8 / 12 / F$ & Celon ProSurge & 1 & 62 & 4.5 & 8.5 \\
\hline $9 / 34 / \mathrm{F}$ & Celon ProSurge & 1 & 14 & 1.4 & 7.7 \\
\hline $10 / 21 / M$ & Celon ProSurge & 2 & 88 & 7.2 & 8.1 \\
\hline $11 / 28 / F$ & Celon ProSurge & 1 & 45 & 3.2 & 7.7 \\
\hline $12 / 7 / M$ & Celon ProSurge & 1 & 14 & 3.8 & 8.1 \\
\hline 13/18/F & Celon ProSurge & 1 & 63 & 5.6 & 8.4 \\
\hline $14 / 17 / M$ & Celon ProSurge & 1 & 38 & 4.2 & 8.0 \\
\hline 15/18/M & Celon ProSurge & 1 & 11 & 5.8 & 9.2 \\
\hline $16 / 22 / F$ & Celon ProSurge & 1 & 47 & 1.0 & 10.2 \\
\hline $8^{\prime} / 13 / \mathrm{F}$ & Celon ProSurge & 1 & 62 & 2.3 & 7.7 \\
\hline $10^{\prime} / 22 / M$ & Laser ablation & 1 & 88 & 12.0 & 7.3 \\
\hline \multicolumn{3}{|l|}{ Mean (min; max) } & $42.5(11.0 ; 88.0)$ & $4.53(1.0 ; 12.0)$ & $7.5(5.0 ; 10.2)$ \\
\hline
\end{tabular}

\section{Clinical success and long-term outcome}

Sixteen patients met the criteria for inclusion in the RFA or ILA. Patients' characteristics and data of the procedures are summarised in detail in Table 2.

The mean pre-procedure VAS score was $8.5 \pm 0.8$. In 14 patients, the VAS score dropped to 0 by the end of first month post procedure. Two patients experienced recurrent pain (VAS $=7-8$ ), and we confirmed that 2 patients had recurrences - both lesions were in the proximal femur. Patient \#8 was retreated with RFA ablation, Patient \#10 was converted to ILA - both patients remained symptom-free and were considered as cured based on their patient records. Two patients (Patient \#3 and Patient \#7) were referred to us with recurrence of pain after previous surgical resection of the nidus in another hospital. There was complete resolution of pain after the first percutaneous treatment in them. One patient developed a minor complication. Long-term follow-up was obtained for 16 patients. The follow-up period was for a maximum of 10.2 years (range 5.0-10.2 years; mean 7.5 years).

\section{Histological findings}

The clinical and radiological criteria were met in the majority of cases, and a biopsy was not performed. Tissue sampling was attempted for a few lesions during the RFA or ILA procedures, and histological confirmation of $\mathrm{OO}$ was determined.

\section{Analysis and management of osteoid osteoma}

All the patients in our study had a standard CT scan. Lesion characteristics are shown in Table 3.

In our study, 14 of the $\mathrm{OO}(83 \%)$ were located in lower extremities, whereas $12 \%(n=2)$ of lesions were in upper limbs. The lesions were located in the femur $(n=8)$, tibia $(n=5)$, talus $(n=2)$, calcaneus $(n=1)$, ulna $(n=1)$, and metacarpal bone $(n=1)$. CT demonstrated in most of the cases a lytic nidus with surrounding reactive sclerosis and adjacent cortical thickening. The imaging criteria indicated intracortical OO in $56 \%$ of patients $(9 / 16)$, subperiosteal in $31 \%(5 / 16)$, and endosteal in $13 \%(2 / 16)$. Eightythree per cent of tumours (14/16) were extra-articular. The procedure was technically successful in all the cases. All tumours were accessed via a single osseous channel, except one lesion for which 2 channels were required.

\section{Discussion}

\section{Excluded procedures}

From 2010 to 2015 , we evaluated 20 patients affected by OO. In the study, ablation to tumour nidi occurring at 
Table 3. Overview of osteoid osteomas (00) treated with radiofrequency thermoablation or interstitial laser ablation

\begin{tabular}{|c|c|c|c|c|c|c|c|}
\hline $\begin{array}{l}\text { Patient number/ } \\
\text { age (years)/ } \\
\text { gender }\end{array}$ & $\begin{array}{l}\text { Bone - tumour } \\
\text { location }\end{array}$ & $\begin{array}{c}00 \text { location type: } \\
\text { subperiosteal, } \\
\text { intracortical, } \\
\text { endosteal, medullary }\end{array}$ & $\begin{array}{l}\text { Intra-articular/ } \\
\text { extra-articular }\end{array}$ & $\begin{array}{l}\text { Nidus, } \\
\text { maximal } \\
\text { axial } \\
\text { diameter } \\
(\mathrm{mm})\end{array}$ & $\begin{array}{l}\text { Nidus, } \\
\text { the } \\
\text { biggest } \\
\text { area } \\
\left(\mathrm{mm}^{2}\right)\end{array}$ & $\begin{array}{c}\text { Nidus, } \\
\text { volume } \\
\left(\mathrm{mm}^{3}\right)\end{array}$ & $\begin{array}{l}\text { Central nidus } \\
\text { calcifications } \\
\text { (mm) }\end{array}$ \\
\hline $1 / 12 / F$ & Femur & Subperiosteal & Extra-articular & 8 & 110 & 547 & 7 \\
\hline $2 / 16 / \mathrm{M}$ & Calcaneus & Endosteal & Extra-articular & 4.4 & 20 & 54 & 1.5 \\
\hline $3 / 32 / \mathrm{M}$ & Tibia & Subperiosteal & Extra-articular & 4 & 40 & 64 & 3 \\
\hline $4 / 26 / M$ & Ulna & Endosteal & Extra-articular & 4 & 22 & 67 & 0.5 \\
\hline $5 / 14 / F$ & Neck of talus & Subperiosteal & Extra-articular & 9 & 78 & 374 & 3 \\
\hline $6 / 5 / M$ & $\begin{array}{l}\text { Trochanter minor } \\
\text { of the femur }\end{array}$ & Intracortical & Extra-articular & 4.5 & 14 & 37 & 0.5 \\
\hline $7 / 21 / M$ & Tibia & Subperiosteal & Extra-articular & 5.4 & 17 & 114 & 1.4 \\
\hline $8 / 12 / F$ & Collum femoris & Intracortical & Intra-articular & 5.7 & 46 & 176 & 4 \\
\hline $9 / 34 / F$ & Metacarpal III & Intracortical & Extra-articular & 2 & 3 & 6 & 0 \\
\hline $10 / 21 / M$ & $\begin{array}{l}\text { Trochanter minor } \\
\text { of the femur }\end{array}$ & Intracortical & Extra-articular & 12 & 178 & 1290 & 0 \\
\hline $11 / 28 / F$ & Femur & Intracortical & Extra-articular & 3.7 & 12 & 39 & 2 \\
\hline 12/7/M & Tibia & Intracortical & Extra-articular & 4.7 & 21 & 66 & 5 \\
\hline $13 / 18 / F$ & $\begin{array}{c}\text { Trochanter minor } \\
\text { of the femur }\end{array}$ & Intracortical & Extra-articular & 6 & 27 & 77 & 3 \\
\hline 14/17/M & Tibia & Intracortical & Extra-articular & 5.6 & 44 & 216 & 2 \\
\hline 15/18/M & Tibia & Intracortical & Extra-articular & 3.4 & 13 & 58 & 0 \\
\hline $16 / 22 / F$ & Collum femoris & Subperiosteal & Intra-articular & 8 & 54 & 274 & 4 \\
\hline $8^{\prime} / 13 / F^{*}$ & Collum femoris & Intracortical & Intra-articular & 5.7 & 34 & 170 & 4 \\
\hline $10^{\prime} / 22 / \mathrm{M}^{*}$ & $\begin{array}{l}\text { Trochanter minor } \\
\text { of the femur }\end{array}$ & Intracortical & Extra-articular & 8.4 & 60 & 476 & 0 \\
\hline \multicolumn{4}{|l|}{ Mean (min; max) } & $5.65(2 ; 12)$ & $44(3 ; 178)$ & $217(6 ; 1290)$ & $2.3(0 ; 7)$ \\
\hline
\end{tabular}

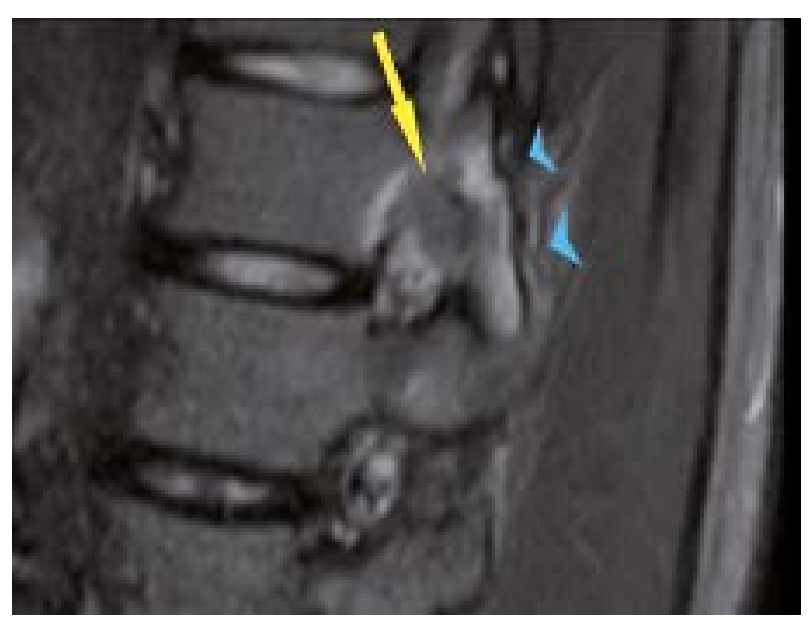

Figure 4. Sagittal T2-weighted spin-echo magnetic resonance image with fat suppression shows nidus with a central area of low signal intensity (arrow) in contact with the nerve root where it passes through the L2-L3 intervertebral foramen. Note bone marrow oedema (arrowheads) in articular processes least $10 \mathrm{~mm}$ from vital tissues (e.g. neurological, skin) had to be limited to avoid tissue damage. Of 20 , we excluded 4 patients from percutaneous ablation because the treatment was declined according to our exclusion criteria. In 1 patient vertebral lesion was in contact with the nerve root where it passes through the L2-L3 intervertebral foramen (Figure 4). One patient had a lesion of the head of the fibula located $9 \mathrm{~mm}$ from the common fibular nerve. In one patient lesion was in contact with the skin. One patient failed to give informed consent.

Due to the positioning of OO located in the pedicle or close to the nerve roots, Rosenthal et al. believed that most patients are not good candidates for RF ablation because of the risk to nerves [17]. While Gangi et al. and Hoffmann et al. found the therapy save, especially when used with an infusion of saline technique via an additional needle to produce an effective insulator [16,25]. Another technique to avoid heat-related skin necrosis, especially in patients with $\mathrm{OO}$ in the radius or tibia, is the sterile 
draping of commercially available cool packs. Cool packs could be positioned around the needle shaft at the entry point to secure the sufficient cooling of overlying skin and soft tissues. Patient selection is a critical step to the successful execution of OO percutaneous treatment.

\section{Short-term outcome}

Lesions in all other anatomical sites were included $(16 / 20)$, percutaneous ablation of the OO had been carried out at our institution, and the patient had been followed for at least 5 years. The present study reports primary and secondary success rates of $87.5 \%$ (14/16 patients) and $100 \%(16 / 16)$, respectively, in OO treated with RFA and laser ablation including technical challenging localisations. Besides OOs in typical locations, we successfully treated 2 intra-articular, 2 post prior unsuccessful orthopaedic resection, and 2 with thin cortical coverage. Lower primary success rates of $67 \%(16 / 24)$ [26], 76\% (74/97) [19], 78\% (18/23) [27], and 79\% (30/38) [28], and comparable success rates of $85-100 \%[17,29,30]$ were reported.

\section{Re-trial of recurred patients}

In this study, there were 2 recurrent patients $(2 / 16)$. In those patients (Patient \#8 and Patient \#10) recurrence appeared within 4 months of follow-up. The second RF treatment (Patient \#8) and laser ablation (Patient \#10) were clinically successful, and no patient had further complaints. The mean period between first and second ablation was 9 months (Patient \#8) and 10 months (Patient \#10). We observed that in Patient \#10 the nidus diminished after first ablation from $1290 \mathrm{~mm}^{3}$ to $476 \mathrm{~mm}^{3}$. The nidus in Patient \#8 diminished insignificantly from $176 \mathrm{~mm}^{3}$ to $170 \mathrm{~mm}^{3}$. No patient had residual pain after a repeat ablation, and no patient needed surgical excision of the lesions.
A recent study showed only a non-diaphyseal location of the $\mathrm{OO}$ as an independent risk factor and at least a trend towards a higher recurrence rate for OO larger than $10 \mathrm{~mm}$ in size [31]. Another study provided evidence of the size of the $\mathrm{OO}$ as the only independent risk factor for an incomplete ablation, with a significantly higher recurrence rate for OOs larger than $10 \mathrm{~mm}$. Location, sex, calcification, and coagulation time were not identified as risk factors [32]. The literature reports 5-25\% recurrence with different treatment modalities [17,33]. Rosenthal reported recurrence in $9 \%$ of cases with open procedures, whereas this rate was $12 \%$ with RFA [34]. Hoffmann conducted a study on CT-guided RFA of OO and reported an $8 \%$ recurrence rate [25]. In his study on interstitial OO laser ablation, Gangi had a 5.3\% early and late recurrence rate [16].

\section{Referrals after failed orthopaedic treatment}

Initial percutaneous ablation was performed in all cases, except for 2 patients $(12.5 \%, 2 / 16)$ with persistent symptoms after they underwent unsuccessful open surgical resection in other hospitals (Figure 5). Both had had open resection of the lesion located in the tibia with no nidus in resected en block. We performed one session of ablation on them and gained good primary results at the follow-up.

\section{Long-term outcome}

It was necessary to analyse long-term follow-ups of RFA and ILA to claim success, because it is possible for recurrence to occur in a 10-year period [20-23]. At the followup between 5 and 10.2 years, $100 \%$ of the patients were classified as good. During the long-term follow-up period, no patients showed late recurrence. The average period of follow-up in our study was 7.5 years, which to the best of

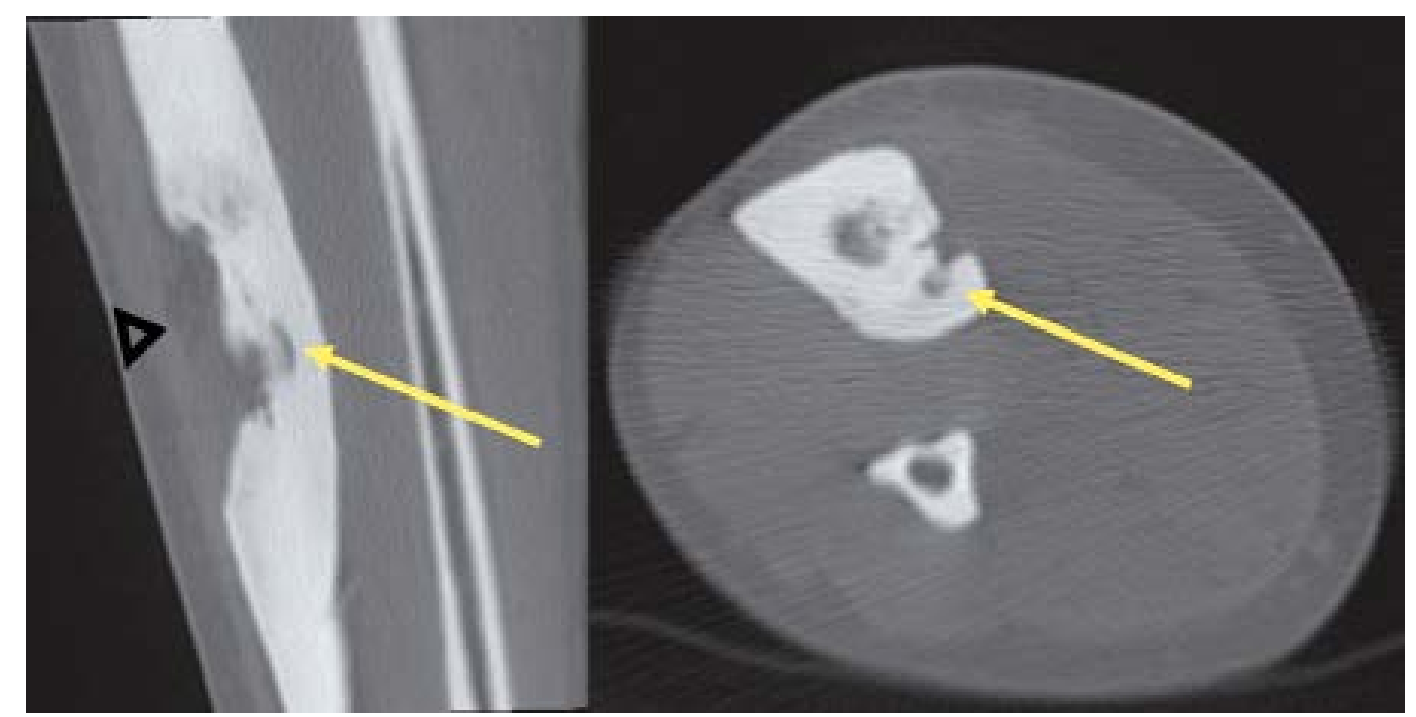

Figure 5. Patient with persistent symptoms after undergoing unsuccessful open surgical resection - biopsy: no nidus in resected en block bone (arrowhead). The nidus is still visible in the tibia (arrows) 
our knowledge is the longest mean follow-up from published studies. Daniilidis et al. described long-term followup after RFA in 29 cases of OO with a mean follow-up of 5.6 years (range 1.0-11.0 years) [35]. Long-term followup was obtained by Abboud et al. for 24 patients - mean time to follow-up was 5 years (range 1.0-12.6 years) [36]. Rimondi et al. performed the largest study of RFA for OO to date, a retrospective review encompassing 557 patients with a mean follow-up period of 3.5 years [37].

\section{Complications}

In 1 patient, there was soft tissue oedema after the procedure accompanied by nonspecific pain not related to OO, and there was no radiologic reflection of this clinical sign. The patient's symptoms were relieved completely after 2 months of a short course of high-dose prednisone in addition to physical therapy. Furthermore, no instances of skin burn next to the electrode entry and no neurovascular compromise developed. Also, in our study, there were no complications; no treatment-related deaths, anaesthesia-related complications, fractures of weight-bearing bones, or other late complications occurred. Previous studies reported complications such as skin burn, skin and fat necrosis, soft tissue infection, vasomotor instability, tendinitis, and haematoma [17,20,33].

\section{Analysis and management of osteoid osteoma}

CT imaging allowed clear identification of the location and size of the lesions. In our study $83 \%$ of OO $(14 / 16)$ were located in lower extremities, which determined spinal anaesthesia. Conversely, two lesions at the upper limb determined regional nerve block. The tumour has a propensity for the major weight-bearing bones, especially the femur. Similarly to cases reported in the literature [8], the most common localisation in our study was the femur (50\%). Two tumours were intra-articular - located within the capsule of the hip joints - and had associated joint effusions. In all cases, CT proved that lytic nidus with surrounding reactive sclerosis and adjacent cortical thicken- ing in the location correlating with the site of the patient's pain. The median nidus volume of these cases was $217 \mathrm{~mm}^{3}$. The largest observed nidus was $1290 \mathrm{~mm}^{3}$ in volume, and the smallest was only $6 \mathrm{~mm}^{3}$. According to other studies the median nidus volume of their cases was $330 \mathrm{~mm}^{3}$ (range 120-2000 $\mathrm{mm}^{3}$ ) [38]. Central nidus calcifications were observed in $14 / 16$ cases, with the largest being $7 \mathrm{~mm}$ in length (mean $2.3 \mathrm{~mm}$ ). The osteoid within the nidus undergoes various degrees of calcification and is associated with the production of irregular trabeculae of woven bone. Previous studies evaluating the treatment success of RFA found that the complete calcification of the nidus upon follow-up CT studies was associated with successful treatment [19]. The thickest perinidal reactive sclerosis and cortical thickness at the entry point was $12 \mathrm{~mm}$ and was observed in the trochanter major of the femur. The thinnest sclerotic changes were $1 \mathrm{~mm}$ and were observed intraarticularly in the neck of the femur. All tumours in the present study were accessed with a single drill hole, except 1 tumour that was greater than $10 \mathrm{~mm}$ in at least one dimension. In this case, 2 osseous channels were drilled for this lesion. These results may suggest that RFA and ILA are efficacious with a single osseous channel procedure applied to the OO smaller than $10 \mathrm{~mm}$, and efficacious if the probe is correctly centred by 2 or more bone drills in the nidus larger than $10 \mathrm{~mm}$. The greatest distance from entry point at skin to the nidus was $88 \mathrm{~mm}$, which was observed around the hip. This can cause problems because the risk of misplacement is higher and sometimes the gantry is too small. The shortest length of needle tract from entry point to the nidus was $11 \mathrm{~mm}$, which was observed in the tibia. Problems with superficially located lesions require focus on proper needle fixation/stabilisation, and sometime extra distancing pad is required. Depending on OO localisation, the shortest distance through the bone was selected for access. When such an approach was considered unsafe due to neurovascular structure proximity, joint capsule, or the approach being technically difficult, the lesion was reached by drilling from the opposite side of the bone (Figure 6).

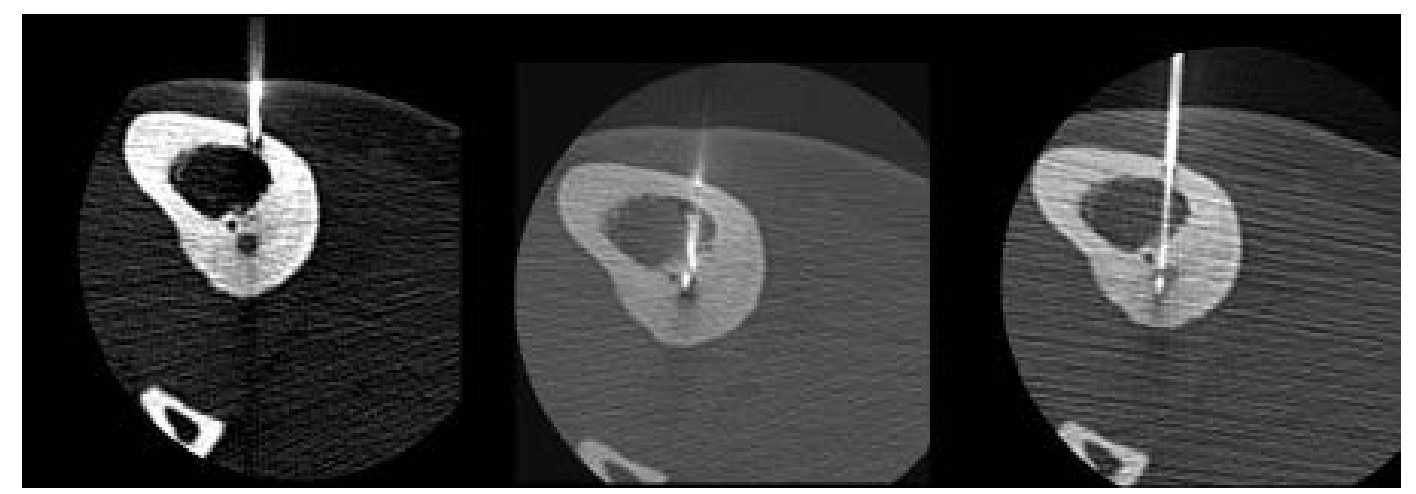

Figure 6. Radiofrequency thermoablation of an osteoid osteoma located in the tibia. Due to the proximity of the neurovascular bundle, a transtibial approach was used to avoid any harm to critical structures 
In some cases, it is difficult to visualise the nidus both in imaging studies and intraoperatively [14]. Computed tomography (CT) most effectively and precisely determines the nidus location and has become the method of choice when X-ray findings are ambiguous, almost completely supplanting the classic planar images $[39,40]$.

\section{Histological findings}

Biopsies for histological confirmation are not routinely performed. The absence of histological confirmation of the diagnosis was not an exclusion criterion. Despite this, some biopsies were performed, and OO diagnosis was confirmed. Several authors conclude that clinical and radiological examinations are enough to make a diagnosis, thus deeming pathological essay not mandatory [33]. This will also reduce patient costs. Despite this, a histopathological examination is still recommended for lesions at atypical sites [17]. At surgical resection or radiofrequency ablation, OO confirmation is obtained in $57-79 \%$ of cases when biopsy is performed $[17,40,41]$. For the remaining patients, no histological diagnosis was determined, due to insufficient material or inadequate specimens.

\section{Advantages of percutaneous ablation}

Currently, the treatment options are varied, and percutaneous treatment is increasingly used. Radiofrequency ablation is widely validated as an efficient method without serious adverse events and with a low rate of recurrence. Laser ablation is used for its ability to focus energy precisely on the ablation area. Rapid post-procedural recovery takes place after its use, and few substantial complications are noted. The tip of the optical fibre acts as a point heat source. The size of the induced zone of ablation depends on the laser wavelength, the thermal and optical properties of the tissue, total duration of energy application, the power used, fibre diameter, fibre tip, and the number of fibres used sequentially or simultaneously for ablation. Recurrences can be treated easily and effectively with follow-up ILA.

\section{Disadvantages of ablation}

The standard of treatment currently consists of a miniinvasive imaging-guided procedure (CT-guided thermoablation), although a percutaneous approach still has some drawbacks. Despite the high success rate of CT-guided thermoablation, there may be minor or major complications from the procedure (e.g. a broken drill, infection, cellulitis, or sympathetic dystrophy). Needle positioning during CT-guided radiofrequency ablation may be challenging, and larger lesions may require multiple treatments or consecutive ablations in the same session, increasing the procedure time. The disadvantages of CT scans concern problems with radiological suite sterility, radiation, accuracy, and increased intra and postoperative complications [16]. Computed tomography is a good way of visualising the nidus and its surrounding soft tissue. However, it has some limitations in needle guidance. Realtime guidance is not possible; therefore, CT-fluoroscopy is used. Some patients must be excluded from the percutaneous ablation because of the inability to undergo a CT-guided procedure due to obesity, making them unable to fit in the gantry. Lack of space in a gantry is sometime exaggerated by long RF needles.

\section{Limitations of radiofrequency thermoablation and interstitial laser ablation techniques}

Often RF ablation reaches "roll-off” (i.e. a significant increase of impedance resulting in the loss of AC flow), indicating complete local coagulation necrosis/charring. In such cases, a manual repositioning of the electrode tip and restarting of the RFA must be done until deposition of the desired energy. A "dry tip" would also cause an early "roll-off", and hence it is essential to wet the probe tip with a saline-soaked gauze and test conductivity before application. Skin burn is known to be a complication of percutaneous RFA procedures [42]. Electricity, leaving a monopolar radiofrequency electrode, travels to a grounding pad placed on the patient's skin, thus completing the circuit. The same amount of energy is deposited at the tip of the electrode and the skin pad, but a larger surface skin pad area dissipates the heat load. However, incorrect skin pad placement or other technical aberrations can result in skin burns [42]. This risk is negated with bipolar systems in which the neutral electrode is located in the ablation probe rather than a skin pad.

The laser fibre is not radiopaque and additional manoeuvres must be adapted to insert the fibre precisely. Despite this, the tip of the bare fibre cannot be monitored within the tumour in real-time. On the other hand, ILA instruments are more compatible with MR imaging than radiofrequency ablation when $\mathrm{MR}$ guidance is considered. A $400-\mu \mathrm{m}$ optical fibre can be introduced through an 18-gauge spinal needle, although a simultaneous biopsy cannot be performed in necessary cases.

\section{Comparison of percutaneous ablation with other treatment methods}

\section{Magnetic resonance-guided focused ultrasound ablation}

Magnetic resonance-guided focused ultrasound (MRgFUS) was described as an alternative form of therapy for symptomatic OO [43]. MRgFUS is a novel imaging-guided ablative technique that allows the performance of noninvasive and radiation-free ablation [44]. MRgFUS uses high acoustic energy for targeted tissue ablation under MR guidance with real-time thermal monitoring. Contrary to focused ultrasound therapy, MRI has the advantage 
of lesion localisation and temperature monitoring. Lesions can be located by intrinsic high tissue MRI contrast. Temperature monitoring, on the other hand, is achieved with the use of specific MRI sequences performed in real time during ablation. MRgFUS is an attractive technique that carries substantial innovation to OO treatment. The success rate demonstrated by early studies was comparable with the results of clinical trials studying CTguided radiofrequency ablation (85\% to $98 \%)[43,44]$. In addition, this technique is noninvasive and requires no incision, eliminating the risk of infection. What is more, it also helps avoid exposing patients to ionising radiation, relevant when considering the young age distribution of those with OO. Claustrophobia, obesity, large sclerotic reaction around the $\mathrm{OO}$, and lesion location close to neurovascular bundles are considered a general limitation of the MRgFUS technique $[43,44]$.

\section{Operative excision}

Some intramedullary and subperiosteal lesions are difficult to localise intraoperatively because they may not demonstrate significant sclerosis. Furthermore, the cortex overlying the site may appear normal during the procedure. Despite a lesion's small size, the operative procedure for its removal can be extensive. Extended curettage and the en bloc resection of the whole lesion are surgical methods of $\mathrm{OO}$ treatment. It is possible that a tumour may recur if it is not completely removed during the operation (Figure 5). The tumour has a propensity for major weight-bearing bones, especially the femur. There is a risk of fracture at such sites if a substantial amount of cortical bone is removed. Therefore, internal fixation and bone grafting may be necessary [34]. The operative length in open surgery is typically longer because exposure and wound closure take time. The need for increased soft tissue dissection and osseous manipulation in open surgery causes more postoperative pain and lengthens hospital stay $[34,45]$. The possibility of histopathological diagnosis is the main advantage of an open procedure.

\section{Conservative treatment}

The painful feature of OO explains the medical community's specific consideration. $\mathrm{OO}$ is a painful benign bone tumour rarely treated, whereby non-steroidal antiinflammatory drugs (NSAIDs) are prescribed to bring relief. Therefore, to treat $\mathrm{OO}$, long-term administration of NSAIDs can often be as effective as excision, without the morbidity that is associated with the operation, especially in patients in whom operative treatment would be complex or could lead to disability [46]. The patient must be under continuous observation and be clearly in- formed about possible side effects. Blood count and liver and kidney functions must be monitored over a patient's treatment period. Side effects from the continuous use of medication are mainly related to gastrointestinal problems. Skin irritations or central nervous system symptoms are extremely rare [10].

\section{Study advantages}

(1) The advantage of this study is a very long follow-up from 5 to 10 years post percutaneous thermoablation. To the best of our knowledge, it is the longest mean follow-up after $\mathrm{OO}$ ablation in the literature. (2) A relatively large sample of patients were treated with bipolar RFA, thus our data give an additional overview of this technique. The majority of the studies to date have used the monopolar system to evaluate the role of RFA in OO. Bipolar RFA of OO has been used in some small series, and only a few publications with a small sample of patients treated with CelonProSurge have been published: $(n=12)$ [47], $(n=1)$ [25]. (3) In our study we proposed automated nidal volume calculations by software-aided CT measurements, and we found this new application to be an easy tool to use for pre-procedural planning and follow-up.

\section{Limitations}

The study has 2 limitations. Firstly, there was no routine histological confirmation. The diagnosis of $\mathrm{OO}$ was made by considering typical clinical symptoms and radiological findings, similarly to other authors $[16,33]$. Secondly is the small patients sample size, although the group size was on a par with other studies in the literature $(n=11)$ [48], $(n=18)$ [38], $(n=23)$ [27], $(n=23)$ [49].

\section{Conclusions}

The percutaneous tumour ablation is a very attractive alternative to surgical resection and conservative treatment. The method relies on percutaneous needle application and thermal destruction of the nidus guided by CT. The longterm results confirm the safety and efficacy of percutaneous radiofrequency ablation in patients with OO, upon a proper evaluation and successful primary and secondary treatment. RFA and ILA lead to better patient management by offering reduced invasiveness. Only 1 minor complication took place, and it is believed that CT guidance is preferable to ensure that energy delivery by probe is within a safe margin from the neurovascular structure or the skin.

\section{Conflict of interest}

The authors report no conflict of interest. 


\section{References}

1. Bergstrand H. Uber Eine Eigenartige, Wahrscheinlich Bisher Nicht Beschriebene Osteoblastische Krankheit in Den Langen Knochen Der Hand Und Des Fusses. Acta Radiologica 1930; 11: 596-613.

2. Jaffe HL. "Osteoid-osteoma”: a benign osteoblastic tumor composed of osteoid and atypical bone. Arch Surg 1935; 31: 709-728.

3. Dahlin DC, Unni KK. Bone tumors: general aspects and data on 8,542 cases. $4^{\text {th }}$ ed. Thomas Pub, Springfield 1986; p. 522.

4. Lorenc T, Palczewski P, Górski R, al. Percutaneous thermoablation of osteoid osteoma - a case study. Ortop Traumatol Rehabil 2012; 14 85-93.

5. Greenspan A. Benign bone-forming lesions: osteoma, osteoid osteoma, and osteoblastoma. Clinical, imaging, pathologic, and differential considerations. Skeletal Radiol 1993; 22: 485-500.

6. Kransdorf MJ, Stull MA, Gilkeyet FW, et al. Osteoid osteoma. Radiographics 1991; 11: 671-696.

7. Goldberg VM, Jacobs B. Osteoid osteoma of the hip in children. Clin Orthop Relat Res 1975; 106: 41-47.

8. Cohen MD, Harrington TM, Ginsburg WW. Osteoid osteoma: 95 cases and a review of the literature. Semin Arthritis Rheum 1983; 12: $265-281$.

9. Kayser F, Resnick D, Haghighi P, et al. Evidence of the subperiosteal origin of osteoid osteomas in tubular bones: analysis by CT and MR imaging. AJR Am J Roentgenol 1998; 170: 609-614.

10. Frassica FJ, Waltrip RL, Sponseller PD, et al. Clinicopathologic features and treatment of osteoid osteoma and osteoblastoma in children and adolescents. Orthop Clin North Am 1996; 27: 559-574.

11. Healey JH, Ghelman B. Osteoid osteoma and osteoblastoma. Current concepts and recent advances. Clin Orthop Relat Res 1986; 204: 76-85

12. Makley JT, Dunn MJ. Prostaglandin synthesis by osteoid osteoma. Lancet 1982; 2: 42.

13. Schulman L, Dorfman HD. Nerve fibers in osteoid osteoma. J Bone Joint Surg Am 1970; 52: 1351-1356.

14. Campanacci M, Ruggieri P, Gasbarrini A, et al., Osteoid osteoma. Direct visual identification and intralesional excision of the nidus with minimal removal of bone. J Bone Joint Surg Br 1999; 81: 814-820.

15. Rosenthal DI, Alexander A, Rosenberg AE, et al. Ablation of osteoid osteomas with a percutaneously placed electrode: a new procedure. Radiology 1992; 183: 29-33.

16. Gangi A, Alizadeh H, Wong L, et al. Osteoid osteoma: percutaneous laser ablation and follow-up in 114 patients. Radiology 2007; 242: 293-301.

17. Rosenthal D, Hornicek FJ, Torriani M, et al. Osteoid osteoma: percutaneous treatment with radiofrequency energy. Radiology 2003; 229: 171-175.

18. Witt JD, Hall-Craggs MA, Ripley P, et al. Interstitial laser photocoagulation for the treatment of osteoid osteoma. J Bone Joint Surg Br 2000; 82: 1125-1128.

19. Vanderschueren GM, Taminiau AHM, Obermann WR, et al. Osteoid osteoma: clinical results with thermocoagulation. Radiology 2002 ; 224: 82-86.

20. Sung KS, Seo JG, Shim JS, et al. Computed-tomography-guided percutaneous radiofrequency thermoablation for the treatment of osteoid osteoma-2 to 5 years follow-up. Int Orthop 2009; 33: 215-218.
21. Neumann D, Berka H, Dorn U, et al. Follow-up of thirty-three computed-tomography-guided percutaneous radiofrequency thermoablations of osteoid osteoma. Int Orthop 2012; 36: 811-815.

22. Rosenthal DI. Percutaneious radiofrequency treatment of osteoid osteomas. Semin Musculoskelet Radiol 1997; 1: 265-272.

23. Regan MW, Galey JP, Oakeshott RD. Recurrent osteoid osteoma. Case report with a ten-year asymptomatic interval. Clin Orthop Relat Res 1990; 253: 221-224.

24. Price DD, McGrath PA, Rafii A, et al. The validation of visual analogue scales as ratio scale measures for chronic and experimental pain. Pain 1983; 17: 45-56.

25. Hoffmann RT, Jakobs TF, Kubisch CH, et al. Radiofrequency ablation in the treatment of osteoid osteoma-5-year experience. Eur J Radiol 2010; 73: 374-379.

26. Kjar RA, Powell GJ, Schilcht SM, et al. Percutaneous radiofrequency ablation for osteoid osteoma: experience with a new treatment. Med J Aust 2006; 184: 563-565.

27. Donkol RH, Al-Nammi A, Moghazi K. Efficacy of percutaneous radiofrequency ablation of osteoid osteoma in children. Pediatr Radiol 2008; 38: 180-185.

28. Cioni R, Armillotta N, Bargellini I, et al. CT-guided radiofrequency ablation of osteoid osteoma: long-term results. Eur Radiol 2004; 14: 1203-1208.

29. Rimondi E, Bianchi G, Malaguti MC, et al. Radiofrequency thermoablation of primary non-spinal osteoid osteoma: optimization of the procedure. Eur Radiol 2005; 15: 1393-1399.

30. Rehnitz C, Sprengel SD, Lehner B, et al. CT-guided radiofrequency ablation of osteoid osteoma and osteoblastoma: clinical success and long-term follow up in 77 patients. Eur J Radiol 2012; 81: 3426-3434.

31. Cribb GL, Goude WH, Cool P, et al. Percutaneous radiofrequency thermocoagulation of osteoid osteomas: factors affecting therapeutic outcome. Skeletal Radiol 2005; 34: 702-706.

32. Vanderschueren GM, Taminiau AHM, Obermann WR, et al. Osteoid osteoma: factors for increased risk of unsuccessful thermal coagulation. Radiology 2004; 233: 757-762.

33. Lindner NJ, Ozaki T, Roedl R, et al. Percutaneous radiofrequency ablation in osteoid osteoma. J Bone Joint Surg Br 2001; 83: 391-396.

34. Rosenthal DI, Hornicek FJ, Wolfeet MW, et al. Percutaneous radiofrequency coagulation of osteoid osteoma compared with operative treatment. J Bone Joint Surg Am 1998; 80: 815-821.

35. Daniilidis K, Martinelli N, Gosheger G, et al. Percutaneous CT-guided radio-frequency ablation of osteoid osteoma of the foot and ankle. Arch Orthop Trauma Surg 2012; 132: 1707-1710.

36. Abboud S, Kosmas Ch, Novak R, et al. Long-term clinical outcomes of dual-cycle radiofrequency ablation technique for treatment of osteoid osteoma. Skeletal Radiol 2016; 45: 599-606.

37. Rimondi E, Mavrogenis AF, Rossi G, et al. Radiofrequency ablation for non-spinal osteoid osteomas in 557 patients. Eur Radiol 2012; 22: 181-188.

38. Wallace AN, Tomasian A, Chang RO, et al. Treatment of osteoid osteomas using a navigational bipolar radiofrequency ablation system. Cardiovasc Intervent Radiol 2016; 39: 768-772.

39. Gamba JL, Martinez S, Apple J, et al. Computed tomography of axial skeletal osteoid osteomas. AJR Am J Roentgenol 1984; 142: 769-772. 
40. Assoun J, Richardi G, Railhac JJ, et al. Osteoid osteoma: MR imaging versus CT. Radiology 1994; 191: 217-223.

41. Mazoyer JF, Kohler R, Bossard D. Osteoid osteoma: CT-guided percutaneous treatment. Radiology 1991; 181: 269-271.

42. Huffman SD, Huffman NP, Lewandowski RJ, et al. Radiofrequency ablation complicated by skin burn. Semin Intervent Radiol 2011; 28: 179-182.

43. Napoli A, Mastantuono M, Cavallo Marincola B, et al. Osteoid osteoma: MR-guided focused ultrasound for entirely noninvasive treatment. Radiology 2013; 267: 514-521.

44. Geiger D, Napoli A, Conchiglia A, et al. MR-guided focused ultrasound (MRgFUS) ablation for the treatment of nonspinal osteoid osteoma: a prospective multicenter evaluation. J Bone Joint Surg Am 2014; 96: 743-751.

45. Lindner NJ, Scarborough M, Ciccarelli JM, et al. CT-controlled thermocoagulation of osteoid osteoma in comparison with tradi- tional methods. Z Orthop Ihre Grenzgeb 1997; 135: 522-527 [Article in German].

46. Kneisl JS, Simon MA. Medical management compared with operative treatment for osteoid-osteoma. J Bone Joint Surg Am 1992; 74: 179-185.

47. Mahnken AH, Tacke JA, Wildberger JE, et al. Radiofrequency ablation of osteoid osteoma: initial results with a bipolar ablation device. J Vasc Interv Radiol 2006; 17: 1465-1470.

48. Cantwell CP, O’Byrne J, Eustace S. Radiofrequency ablation of osteoid osteoma with cooled probes and impedance-control energy delivery. AJR Am J Roentgenol 2006; 186 (5 Suppl): S244-248.

49. Mylona S, Patsoura S, Galani P, et al. Osteoid osteomas in common and in technically challenging locations treated with computed tomography-guided percutaneous radiofrequency ablation. Skeletal Radiol 2010; 39: 443-449. 